\title{
REPRESENTATIVIDADE DO IPTU NA RECEITA TRIBUTÁRIA DOS MUNICÍPIOS DE MIRASSOL D'OESTE, ARAPUTANGA E SÃO JOSÉ DOS QUATRO MARCOS
}

$\begin{array}{ll}\text { Nome } & \text { Gilson Lourenço Ribeiro } \\ \text { Instituição/Afiliação } & \text { Universidade do Estado de Mato Grosso } \\ \text { País } & \text { Brasil } \\ \text { Resumo da } & - \\ \text { Biografia } & \end{array}$

\section{RESUMO}

A Receita Tributária Municipal e a arrecadação do Imposto Predial Territorial Urbano (IPTU) dos municípios de Araputanga, Mirassol D’Oeste e São José dos Quatro Marcos, no período de 2011 a 2014, foram objeto de estudo deste trabalho acadêmico. Os municípios selecionados fazem parte da microrregião designada Vale do Jauru, a Oeste do Estado de Mato Grosso e possuem características geográficas e sociais semelhantes. O objetivo era analisar a representatividade desse tributo para o montante da arrecadação tributária própria. $\mathrm{Na}$ fase de coleta dos dados foi realizado uma pesquisa quantitativa nos sítios eletrônicos das prefeituras, Câmaras Municipais e Tribunal de Contas do Estado de Mato Grosso, onde foi pesquisado o valor arrecadado em Receita Tributária e o valor específico do IPTU. Quanto ao método de análise, foi utilizado o método quantitativo, sendo realizado uma análise descritiva dos dados encontrados. Observou-se que essa fonte de recurso é relevante para a Receita Tributária própria dos munícipios sob análise.

Palavras-chave: IPTU, Gestão Pública, Receita Tributária Municipal.

\section{INTRODUÇÃO}

O Estado com a representatividade que conhecemos hoje é o resultado de inúmeros fatos históricos que aconteceram ao longo dos séculos. Seu desenvolvimento tem início a cerca de 5000 anos, com a revolução agrícola e a revolução urbana, possibilitaram maior fixação do homem a terra e consequentemente a formação dos aglomerados urbanos com a necessidade de fortalecer a relação de troca (comércio), que resultaram na necessidade de um poder que pudesse centralizar as diretrizes das atividades militares e econômicas (MAZOYER, ROUDART, 2010).

O Estado é assim uma necessidade do ser humano que convive em sociedade como forma de organizar, desenvolver e controlar o convívio harmonioso.

No decorrer dos séculos as transformações sociais - como as grandes navegações, a Revolução Industrial, a Revolução Francesa, a ascensão do capitalismo - levaram ao atual Estado Democrático de Direito brasileiro, apregoado na Constituição Federal de 1988. 
Nossa Lei Maior atribui ao Estado brasileiro o dever de assegurar a todos o exercício dos direitos sociais e individuais, a cidadania e o bem-estar sem quaisquer tipos de discriminação.

Para atender os objetivos estabelecidos na Constituição Federal de 1988, o Estado brasileiro conta com seus órgãos públicos e com seus entes federados. A Constituição Federal estabelece uma igualdade de tratamento entre o Município e os demais entes federativos, assegurando-lhe autonomia governamental, administrativa e legislativa no âmbito de sua competência, em seus artigos 29, I e 30 e incisos.

E para assegurar o atendimento as necessidades do povo, conforme determinado na Constituição Federal de 1988 é preciso que o Estado realize desembolso financeiros.

Para tanto é necessário que o Estado desenvolva atividade financeira e obtenha recursos, por meio de arrecadação de tributos. Os tributos se consolidam como a principal fonte de recursos para a Administração Pública, sendo contabilizados como receitas tributárias.

O Estado exerce o poder de tributar as atividades privadas mas em contrapartida obriga-se a oferecer uma contra prestação ao cidadão, buscando assegurar ao mesmo os direitos garantidos por meio da Constituição Federal, possibilitando um convívio social mais harmônico e digno ao contribuinte, de forma que não haja lesão ao patrimônio privado.

Os cofres públicos municipais são abastecidos pelas transferências compulsórias do Governo Federal e das transferências do Governo Estadual, além da arrecadação de recursos próprios por meio da cobrança de tributos. Sendo que a Carta Magna define em seu art. 156 os limites do poder municipal em legislar.

Entre os impostos permitidos aos municípios está o Imposto Predial Territorial Urbano (IPTU) - art. 156, I, da CF/88. Administrar um sistema eficiente de arrecadação de impostos sobre o patrimônio e as taxas municipais é uma missão que exige decisão e ação político-administrativa.

Com a diminuição da arrecadação há também diminuição nos repasses, cabendo aos municípios adotar uma política tributária eficiente e gerenciar com mais habilidade os recursos financeiros disponíveis. Em momentos como este é necessário dar mais atenção a arrecadação própria. Muitas vezes o gestor deixa de priorizar a cobrança de imposto por decisões político-eleitoral, já que aumentar a efetividade da cobrança de imposto não garante votos. 
O IPTU é visto pela população como uma grande fonte de receita para o município já que é cobrado de maneira direta do cidadão e ao mesmo tempo não é vinculado a nenhuma prestação de serviços ou bens de utilidade pública.

Ante todo o exposto acima esta pesquisa visa aprofundar o estudo sobre a representatividade do IPTU para as receitas tributárias do município de Mirassol D’Oeste, Araputanga e São José dos Quatro Marcos-MT, no período de 2011 a 2014 e o impacto dessa arrecadação nos cofres municipais, investigará se a arrecadação do IPTU é representativo para a receita tributária desses municípios.

Neste contexto o objetivo geral é analisar a representatividade da arrecadação do IPTU para a receita tributária total do município de Mirassol D’Oeste, São José dos Quatro Marcos e Araputanga no período de 2011 a 2014.

Para tanto, são objetivos específicos deste trabalho: Conceituar o que é tributo, taxas e contribuições; demonstrar a importância da arrecadação do IPTU para os cofres do município de Mirassol D’Oeste, São José dos Quatro Marcos e Araputanga; e, evidenciar a importância de uma gestão eficiente da arrecadação própria diante do cenário crise econômica pela qual passa o país.

A pesquisa limita-se a analisar se é representativo, dentro das receitas tributárias próprias, o valor arrecadado pela administração dos municípios de Mirassol D’Oeste, São José dos Quatro Marcos por meio do Imposto Predial e Territorial Urbano.

\section{FUNDAMENTAÇÃO TEÓRICA}

A Constituição Federal de 1988 atribuiu aos municípios brasileiros o poder de emitir sua própria Lei Orgânica Municipal, que equipara-se a Constituição Municipal. Esse regramento jurídico dita, prescreve os princípios gerais sobre a organização municipal, as normas administrativas, a administração tributária e financeira do município, a composição da Câmara de Vereadores, a participação social e a adoção de políticas públicas visando o desenvolvimento socioeconômico do município.

Com o deslocamento do poder do âmbito geral para o local, ente mais suscetível a influência do contribuinte, coloca os municípios com maior know-how para coordenar as políticas sociais com maior precisão, permitindo que o gestor local valorize mais o seu cidadão, assegurando a eles o acesso a saúde, trabalho, educação e os direitos sociais dispostos na Carta Magna da República brasileira (JUNQUEIRA, INOJOSA e KOMATSU, 1998). 
As competências privativas dos municípios são aquelas que estão estabelecidas na Constituição Municipal e referem-se tão somente ao interesse local. Esse ente federado organiza e presta diretamente, ou sob a forma de concessão ou permissão, todos aqueles serviços de interesse local. Historicamente já compunham as atribuições municipais os serviços de iluminação, limpeza, organização do trânsito, entre outros, sendo acrescido a este serviços o de habitação, saúde, educação, em que o Governo Federal não conseguia fazer com alcance em todas as cidades (JUNQUEIRA, INOJOSA E KOMATSU, 1998).

A administração pública municipal é gerida pelo chefe do executivo, o prefeito, eleito pelo voto popular para um mandato de quatro anos, através de um máquina administrativa formada por órgãos (secretarias, departamentos, serviços, etc.) e entidades (empresas estatais, autarquias e fundações), que opera diretamente em favor do cidadão, atendendo as especificidades locais em termos de necessidade.

De acordo com o disposto no Art. 23 da CF/88, em complemento em atendimento aos problemas sociais locais os gestores municipais, devem assumir ainda compromissos de maneira integrada visando o bem estar social do seu povo e também da nação.

Já em seu Art. 30, a Carta Magna confere aos municípios poderes e obrigações e ainda define quais são as competências privativas atribuídas a eles.

Assim o município fica responsável por realizar todos os propósitos estabelecidos LOA - Lei Orçamentária Anual - mediante o interesse público, zelando pelos princípios de eficiência e eficácia, utilizando os recursos disponíveis através de instrumentos e ferramentas de gestão adequados a realidade local.

Com o federalismo brasileiro temos uma descentralização fiscal, seja por meio da receita como também da despesa. Mas mesmo assim a receita tributária própria dos municípios brasileiros ainda é pequena quando comparada aos demais entes federativos.

Oliveira, (2015. Pág. 17) nos mostra que:

As municipalidades no Brasil sempre foram dependentes de transferências para a manutenção de suas atividades. Isto mudou, em parte, com a Constituição de 1988. Dados do ano 2000 mostram que a receita tributária própria é em torno de 5\% do total nacional, em contrapartida a receita total disponível é por volta de $17 \%$.

Há uma necessidade crescente, especialmente após a Lei de Responsabilidade Fiscal (LRF), que os municípios realizam uma gestão mais eficiente tanto na arrecadação dos tributos quanto na realização dos gastos públicos. 


\subsection{Receitas municipais}

Nazareth e Porto (2002) nos ensina que por meio da Constituição Federal de 1988, em seus artigos $1^{\circ}$ e $8^{\circ}$, está estabelecido que nosso país é uma República Federativa tendo sua organização indissolúvel, da União, Estados e Municípios. A Carta Maior designou também a descentralização das partes: reconhece os estados como entes federativos e atribui-lhes renda e competências, assim como os municípios, entidades político-administrativas intraestadual, atribuindo-lhes também competências e rendas, ambas dotadas de autonomia política, administrativa e financeira.

Essa autonomia trazida pela Constituição Federal de 1988 oportunizou aos municípios maior participação nas receitas e nos gastos públicos.

Na Carta Maior ficou estabelecido os municípios como organizações federativas dotadas de autonomia e modificou substancialmente sua estrutura e funcionamento, como evidencia Nazareth e Porto (2002, p. 5):

\footnotetext{
- reconheceu a capacidade de auto-organização dos governos municipais, estabelecendo a Lei Orgânica Municipal, tratada no âmbito local, uma espécie de Constituição do Município;

- ampliou a concorrência tributária da esfera municipal de governo, conferindo-lhe o poder exclusivo de instituir e cobrar impostos sobre a propriedade territorial e urbana - IPTU, sobre a transmissão de inter-vivos de bens imóveis - ITBI e sobre serviços de qualquer natureza - ISS, prevendo ainda a possibilidade de delegação de competências da União e dos Estados e a ampliação das chamadas competências concorrentes, conferidas em comum aos três níveis de governo;

- complementou a repartição da competência tributária com o aprofundamento do sistema de quotas de participação, aumentando as transferências intergovernamentais de receitas com o objetivo de equalizar os recursos disponíveis para os municípios, fundamentais para o desempenho de suas atribuições.
}

Tais medidas fortaleceram o processo de descentralização político administrativa almejado junto com o processo de redemocratização do país, colocando fim ao poder centralizador estabelecido no Regime Militar, possibilitando aos entes federados (estados e municípios) exercer uma gestão financeira mais autônoma.

Entre as espécies de tributos, definidas no art. 145 da CF/88, os impostos se destacam como a principal fonte de recursos para custeio da Administração Pública. São também uma fonte de recursos não diretamente vinculadas a uma determinada contraprestação de bens ou serviços públicos, possibilitando assim que tais recursos financeiros sejam aplicados em qualquer área de atuação da entidade pública federada. 
Mesmo com a autorização/determinação expresso na Constituição Federal de 1988 para que os municípios possam instituir e cobrar tributos municipais alguns municípios permaneceram apresentando dificuldades financeiras e consequentemente necessitando de apoio das outras esferas governamentais. A preconizada autonomia financeira foi sendo mais solidificada a partir da transferências intragovernamentais, reguladas por meio do Fundo de Participação dos Municípios.

\subsection{Receitas tributárias dos municípios}

Consoante dispõe a Lei 4.320/1964, as receitas tributárias podem ser compreendidas como sendo as entradas de recursos oriundos da arrecadação de tributos cuja competência é privativa de entes da federação. Assim, o município, como ente federado, possui parcela dessas receitas para atender determinadas demandas sociais de sua localidade contribuindo para o bem estar do cidadão.

É sobre os recursos tributários que o gestor local tem maior autonomia para exercer o poder discricionário. Assumindo seu poder de tributar, assegurado constitucionalmente, é que os municípios podem influenciar o montante a ser arrecadado de forma que se ajuste as suas necessidades dentro dos limites legais.

A Carta Magna em seu Art. 30, II, quando afirma que os municípios são responsáveis pela instituição e arrecadação de tributos, atribuiu aos mesmos a responsabilidade pela organização do seu sistema próprio de arrecadação de receitas.

O município deverá instituir seu próprio Código Tributário afim de regulamentar seu sistema de arrecadação de tributos e que esse montante arrecadado é restrito a municipalidade que assim o recolher.

De acordo com o Araújo e Afonso (2001. Pág. 02) “a receita municipal (não computadas as transferências recebidas) vem apresentando excelente desempenho nos últimos anos." O volume de recursos da receita tributária própria cresce na medida que os gestores investem na modernização fazendária.

Em estudo mais profundo Araújo e Afonso (2001. Pág. 03) demonstram que:

o exame mais detalhado da situação brasileira mostra que a arrecadação tributária própria dos municípios provém sobretudo, dos impostos sobre a venda de serviços ISS - e sobre a propriedade imobiliária urbana - IPTU.

Além desses tributos os municípios arrecadam também por meio do Imposto de Transmissão de Bens Imóveis - ITBI -, taxas e contribuições. 
Receita tributária pode ser definida como sendo as entradas provenientes da arrecadação de impostos, taxas e contribuições de melhoria. Dessa forma, é uma receita privativa das entidades investidas do poder de tributar: União, Estados, Distrito Federal e os Municípios.

Para ampliar a arrecadação própria municipal é necessário investimentos em tecnologia e conhecimento, é necessário modernizar a gestão tributária no município garantindo maior acompanhamento e fiscalização. Como nos ensina Araújo e Afonso (2001. Pag. 7):

Em muitos casos é preciso investimentos em cadastramentos, sistemas de controle, fiscalização, treinamento de pessoal. Tratam-se de aplicações de elevadíssimo retorno, mesmo para os critérios mais rígidos de análise de investimentos.

Como forma de contribuir nessa modernização o BNDES -Banco Nacional de Desenvolvimento Social - e alinhado a proposta do Governo Federal lançou no ano de 1997 o Programa de Modernização da Administração Tributária e da Gestão dos Setores Sociais Básicos - PMAT.

\subsection{Tributo}

O conceito de tributo está relacionado com o radical latino tributum, que remete a ideia de algo que é concedido ou rendido por obrigação, hábito ou imposição legal. Segundo CORRÊA (1971) na Roma Antiga tributo era o imposto pago pelo derrotado ao vencedor por vezes era uma forma de prestação para cobrir as despesas de guerra.

A Constituição Federal de 1988 no Título VI trata do Sistema Tributário Nacional (STN). Tal sistema é formado por tributos federais, estaduais e municipais. A lei $\mathrm{n}^{\circ}$ 5.172/66, denominada Código Tributário Nacional (CTN), dispõe sobre o STN e institui normas gerais de direito tributário aplicáveis à União, Estados e Municípios. Em seu art. $3^{\circ}$, dispõe sobre a definição de tributo:

Art. $3^{\circ}$ Tributo é toda prestação pecuniária compulsória, em moeda ou cujo valor nela se possa exprimir, que não constitua sanção de ato ilícito, instituída em lei e cobrada mediante atividade administrativa plenamente vinculada (BRASIL, 1966).

Pode se dizer que tributo tem como características essenciais a obrigatoriedade da prestação em moeda e a imposição pela Fazenda Pública. É a transferência de recursos financeiros em moeda para saldar uma exigência legal do Estado.

Para Duarte e Alcântara tributo pode ser definido (2013, p. 81) como,

Trata-se de prestação pecuniária, justamente para atender à consecução dos objetivos do Estado, eis que se trata de prestação em moeda. É compulsória, no sentido de que não tem natureza de disposição de vontade do contribuinte, como as doações e receitas 
contratuais. Distingue-se de penalidade, tendo em vista a hipótese de incidência, eis que ao contrário daquela, decorre de ato lícito.

Então, entende-se que o tributo é necessariamente pago em moeda corrente, devendo ter valor que possa representar. Somente pode ser cobrado por atividade, renda ou patrimônio que seja lícito, por ilícitos é instituído uma penalidade.

Ainda de acordo com o CTN, no seu art. $5^{\circ}$ (BRASIL, 1966), são definidos três tipos de tributos: impostos, taxas e contribuições de melhoria.

Conforme se denota do art. 145 da CF/88 o STN está distribuído entre os entes da federação: União, Estados, Distrito Federal e Municípios. Estes por sua vez podem instituir a cobranças de tributos de sua competência.

Em âmbito local, a Lei Complementar Municipal n 134/2013 (Código Tributário do Município de Mirassol D'Oeste) dispõe sobre os tributos da competência municipal.

\subsubsection{Impostos}

Os impostos são uma espécie de tributos que não necessitam de uma atividade estatal para existir o fato gerador, tendo como base fática um comportamento do contribuinte, ou mesmo uma situação jurídica em que ele se encontre. Para existir o imposto existe um fato qualquer envolvendo o particular, sem a participação do Estado.

De acordo com o CTN: "Art. 16. Imposto é o tributo cuja obrigação tem fato gerador independente de qualquer atividade estatal específica ao contribuinte" (BRASIL, 1966).

O que este artigo nos traz é que imposto não está diretamente relacionado com uma prestação de serviço específica do Estado para o contribuinte, ratificando, desse modo, a não vinculação da receita, atendendo ao princípio orçamentário da não afetação da receita pública. Conforme nos ensina Duarte e Alcântara (2013. p. 80) (...) "trata-se de tributo não-vinculado, e ainda pode-se dizer que é gerado em função da capacidade contributiva de cada pessoa." É cobrado em razão do fato social de caráter econômico. O art. 167 da CF/88 corrobora com essa ideia ao afirmar que é vedado a vinculação de receita de impostos a órgão, fundo ou despesa, ressalvadas a repartição do produto da arrecadação dos impostos e destinação de recursos para ações e serviços específicos, definidos na própria Constituição. 
Mesmo não sendo vinculados os impostos devem obedecer ao princípio da capacidade contributiva, onde o Estado deve dar tratamento justo ao contribuinte, tratando de maneira desigual os desiguais.

Já no Art. $145, \S 1^{\circ}$, da CF/88, está ligado com a imposição do ônus tributário sobre a pessoa que deve suporta-lo. $\mathrm{O}$ imposto, portanto, pode ser considerado como justo na medida em que está adequado à capacidade econômica de quem deve efetuar o pagamento.

Os impostos são classificados como diretos e indiretos. SIQUEIRA, NOGUEIRA E SOUZA, (2001. p. 112) nos ensina que:

Impostos indiretos são aqueles cobrados/ de produtores com relação à produção, venda, compra ou uso de bens e serviços. ${ }^{1}$ Frequentemente, impostos indiretos são arrecadados em vários estágios do processo de produção e venda, de forma que seus efeitos sobre os preços pagos pelo consumidor final na cadeia de transações não são claros.

Imposto direto é aquele que incide numa dada situação, é cobrado do contribuinte legalmente definido. $\mathrm{O}$ imposto direto tem um contribuinte que suporta a carga do tributo, como é o caso do IPTU. Já o imposto indireto tem também um contribuinte, ele recolhe o imposto, mas esse tributo acaba repercutindo no bolso de terceiros, como no caso do Imposto de Importação, Imposto de Renda, entre outros.

Vimos que os impostos são a principal fonte de recursos do Estado para atender as demandas sociais.

\subsubsection{IPTU}

O IPTU é um imposto de competência municipal, conforme expresso pela CF/88 em seu art. 156, isto é, somente os municípios têm competência para aplica-lo. Excetua a competência apenas o Distrito Federal, por seu caráter sui generis com atribuições de Estado e município.

O IPTU é um dos impostos que atinge a grande maioria da população e é sentido no bolso já que a cobrança é feita diretamente ao contribuinte. De acordo com Carvalho (2006. p. 07) “...o IPTU é um imposto altamente visível e com arrecadação estável ao longo do tempo. Sua arrecadação no Brasil é muito baixa, existindo amplo espaço para o seu incremento”.

Trata-se de imposto que contribui em grande parte com a arrecadação dos governos locais. A atribuição dada aos gestores municipais está relacionada com o conhecimento da área urbana municipal o que facilita a fiscalização e cobrança (CARVALHO. 2006. p. 8). 
Por meio desse imposto o poder público pode recuperar parte dos investimentos realizados e com isso permanecer investindo em outras áreas da urbe, desde que tenha uma gestão com planejamento estratégico. Carvalho (2006, p. 15) afirma que:

\begin{abstract}
O IPTU, portanto, pode ser usado para recuperar parte dos investimentos em obras públicas, porque a valorização imobiliária ocorrida refletiria na base de cálculo do imposto, pois, se as avaliações imobiliárias oficiais fossem precisas, realizadas num curto espaço de tempo (atuais) e refletissem os valores de mercado, o IPTU seria um instrumento bem direto de recuperação de mais-valias. Entretanto, para a captação de parte da valorização imobiliária ser efetiva, é necessário que o município atualize a sua Planta de Valores Genérica, instituindo novos valores venais por meio de um projeto de lei municipal aprovado pela Câmara de Vereadores.
\end{abstract}

Como nos ensina Carvalho (2006) o IPTU constitui-se como uma das principais fontes de receita tributária municipal e desempenha uma importante função social na medida em que seus recursos são redistribuídos pela cidade proporcionando a realização de uma adequada política de desenvolvimento urbano em cada localidade.

\title{
3. METODOLOGIA
}

Esse tópico expõe os métodos a serem utilizados, as abordagens matemáticas, econômicas e estatísticas que serão utilizadas para a análise dos dados coletados no site do Tribunal de Contas do Estado (TCE) de Mato Grosso referente aos municípios de São José dos Quatro Marcos, Araputanga e Mirassol D’Oeste.

O trabalho de pesquisa é uma busca, uma averiguação, um exame. Trata-se de investigação fundamentada e organizada da causa e do efeito, da existência ou não de um problema aponta que incomoda o investigador. É o "procedimento racional e sistemático que tem como objetivo proporcionar respostas aos problemas que são propostos” (GIL, 2002, p. 17)

Por metodologia está o conjunto de técnicas e meios utilizados para a realização deste trabalho. Segundo DALFOVO, LANA e SILVEIRA apud Richardson (2008, p. 29) “(...) método em pesquisa significa a escolha de procedimentos sistemáticos para a descrição e explicação de fenômenos. Assim a pesquisa deve seguir aquilo que foi planejado e deve se ater aos métodos científicos necessários.

\subsection{Classificação da pesquisa}

A investigação se caracteriza por uma abordagem com objetivos claramente definidos, técnicas e procedimentos formais de coleta e avaliação de dados. 
Para realizar este trabalho vamos realizar uma pesquisa aplicada que visa compreender a representatividade da arrecadação do IPTU para a receita tributária dos municípios de Araputanga, São José dos Quatro Marcos e Mirassol D’Oeste-MT, no período de 2011 a 2014.

Para finalizar o trabalho necessário se faz a análise dos dados e a elaboração de gráficos e tabelas de maneira a facilitar a visualização, leitura e compreensão das informações obtidas e analisadas.

\subsection{Procedimentos e abordagem da pesquisa}

De acordo com Beuren et al (2006) um trabalho cientifico compreende três categorias:

(...) pesquisa quanto aos objetivos que contempla a pesquisa exploratória, descritiva e explicativa; pesquisa quanto aos procedimentos, que aborda o estudo de caso, o levantamento, a pesquisa bibliográfica, documental, participante e experimental; e, pesquisa quanto a abordagem do problema, que compreende a pesquisa qualitativa e a quantitativa (BEUREN e et al., 2006).

$\mathrm{Na}$ Introdução a este trabalho foi demonstrado como alguns escritos mostram as dificuldades financeiras pelas quais alguns gestores municipais passam. Isso é atribuído ao fato de que os recursos repassados por meio das transferências constitucionais não conseguem suprir todas as demandas locais, que deveria então ser supridas pela arrecadação tributária própria.

Nesse sentido este trabalho é classificado como uma pesquisa descritiva. Tal tipologia consiste em descrever as características de determinado população ou fenômeno ou ainda o relacionamento entre variáveis (GIL, 2002). Assim sendo este trabalho científico preocupa-se em descrever as características das receitas tributárias arrecadadas por meio do Imposto Predial Territorial Urbano nos municípios de Araputanga, São José dos Quatro Marcos e Mirassol D'Oeste.

Do ponto de vista de procedimentos metodológico será utilizado uma pesquisa documental a partir da leitura e análise de obras (artigos, monografias, teses) disponíveis em site de universidades e revistas cientificas, bem como os dados disponíveis no site do Tribunal de Contas do Estado de Mato Grosso e das Prefeituras dos municípios de Araputanga, Mirassol D’Oeste e São José dos Quatro Marcos-MT. Assim “Consiste em pesquisar em material escrito: livros, dissertações de mestrado, teses de doutorado, periódicos, relatórios, anais de congressos, documentos de qualquer natureza e internet", de acordo com Duarte (2014, p. 17) apud Didio.

A pesquisa documental é uma técnica imprescindível para o trabalho de investigação já que as fontes, sejam elas escritas ou não, são a base do trabalho. Segundo Godoy (1995, p. 21) 
"O exame de materiais de natureza diversa, que ainda não receberam um tratamento analítico, ou que podem ser reexaminados, buscando-se novas e/ ou interpretações complementares, constitui o que estamos denominando pesquisa documental." Os documentos representam uma rica fonte de dados e a análise dos mesmos permite uma reflexão que retrata o momento em que os fatos aconteceram.

Através do método quantitativo há o uso de instrumentos estatísticos, tanto na fase de coleta de dados, quanto no momento de análise e avaliação dos mesmos. Por meio do método dedutivo o estudo de caso visa partir do contexto geral para analisar as particularidades do IPTU para os municípios sob análise.

Esta pesquisa compreende-se como um estudo de caso na medida que faz a busca de dados documentais e tem como objeto de estudo a situação da representatividade do IPTU para a arrecadação tributária de três municípios inseridos na microrregião do Vale do Jauru.

Para representar o resultado deste trabalho é necessária uma pesquisa quantitativa que possa traduzir em números os resultados alcançados. Para DALFOVO, LANA e SILVEIRA (2008) a pesquisa quantitativa é aquela em que “(...) tudo que pode ser mensurado em números, classificados e analisados, utiliza-se de técnicas estatísticas”.

\subsection{Universo e amostra}

Para a realização deste trabalho o universo analisado foram os 12 municípios da região denominada Vale do Jauru, a oeste do estado de Mato Grosso.

Como amostragem selecionamos os municípios de Araputanga, São José dos Quatro Marcos e Mirassol D’Oeste por tratar-se de municípios circunvizinhos que tem um perfil sócio econômico e com área urbana com dimensões semelhantes.

\subsection{Instrumento e processo de coleta de dados}

Os dados utilizados neste trabalho científico foram obtidos em pesquisa ao sítio eletrônico oficial do Tribunal de Contas do Estado de Mato Grosso (TCE-MT), por meio dos balanços ali disponibilizados.

Outra fonte acessada foi o sítio eletrônico do Instituto Brasileiro de Geografia e Estatística (IBGE) de acordo com o censo demográfico de 2010. 
Por último buscamos informações disponibilizadas no Portal da Transparência dos municípios que compõe a amostra desta investigação científica a fim de analisar as informações ali disponíveis e a facilidade de acesso as informações disponibilizas ao contribuinte.

\section{APRESENTAÇÃO DOS RESULTADOS E DISCUSSÃO}

Esse trabalho teve sua gênese quando identificamos a problemática proposta, abordando primariamente o tema fundamental, conceitos, proposições, métodos e técnicas para concretizar o objetivo proposto com a análise e interpretação dos dados coletados.

A análise tem como objetivo organizar e sumarizar os dados de tal forma que possibilitem o fornecimento de respostas ao problema proposto para investigação. Já a interpretação tem como objetivo a procura do sentido mais amplo das respostas, o que é feito mediante sua ligação a outros conhecimentos anteriormente obtidos (GIL, 1997 apud LONGARY et al., 2003. p. 57).

Os municípios pesquisados estão localizados na microrregião denominada de Vale do Jauru a Oeste do Estado de Mato Grosso e possuem características semelhantes em termos de dimensão geográfica, populacional e econômica.

O período analisado, 2011 a 2014, contempla o período de duas gestões públicas municipais, sendo dois anos de cada gestão.

De acordo com os dados disponibilizados pelo IBGE o município de Araputanga conta com 16.109 habitantes e recebeu status de município pela lei estadual $n^{\circ} 4153$ de 14 de dezembro de 1979, com território desmembrado do município de Mirassol d'Oeste. Em 2014, tinha um PIB per capita de $\mathrm{R} \$ 21.578 .15$.

O município de Mirassol D’Oeste foi fundado em 28 de outubro de 1964, sendo emancipado em 14 de maio de 1976. Está localizado na microrregião Vale do Jauru e está a 296 quilômetros da capital do estado, Cuiabá. Segundo os dados do IBGE a população estimada atual é de 26.596, em 2014 tinha um PIB per capita de R\$21.574.17.

O município de São José dos Quatro Marcos foi criado em 14 de dezembro de 1979 por meio da Lei Estadual no 4.154/79. Tem uma população estimada em 18.536 habitantes e em 2014, tinha um PIB per capita de R\$18.350.24, segundo dados do IBGE. 
No período estudado a receita tributária do município de Araputanga sofreu uma variação positiva de $41.24 \%$ enquanto a arrecadação por meio do IPTU cresceu no mesmo período 74,49\%, ou seja, o crescimento da arrecadação do IPTU superou, e muito, o crescimento da receita tributária total. Já em termos de representatividade do IPTU em relação ao Receita Tributária Municipal a mesma era de 8,01 e encerrou o período em 9,90\%.

A tabela 1 demonstra que a arrecadação do IPTU esteve crescente no período, saindo do percentual de $8,01 \%$, no ano de 2011, para o montante de $9,90 \%$, no ano de 2014, da Receita Tributária.

Tabela 1 - Receita Tributária do Município de Araputanga de 2011 - 2014

\begin{tabular}{c|cc|rc|c}
\hline Ano & \multicolumn{2}{|c|}{$\begin{array}{c}\text { Receita tributária } \\
\text { Municipal }\end{array}$} & \multicolumn{2}{|c|}{ IPTU } & $\begin{array}{c}\text { Representatividade do } \\
\text { IPTU }\end{array}$ \\
\hline 2011 & $\mathrm{R} \$$ & $2.223 .315,45$ & $\mathrm{R} \$$ & $178.127,57$ & 8,01 \\
\hline 2012 & $\mathrm{R} \$$ & $2.957 .056,46$ & $\mathrm{R} \$$ & $196.337,36$ & 6,64 \\
\hline 2013 & $\mathrm{R} \$$ & $2.950 .477,97$ & $\mathrm{R} \$$ & $287.899,85$ & 9,76 \\
\hline 2014 & $\mathrm{R} \$$ & $3.140 .297,61$ & $\mathrm{R} \$$ & $310.823,05$ & 9,90 \\
\hline Total & $\mathrm{R} \$$ & $\mathbf{1 1 . 2 7 1 . 1 4 7 , 4 9}$ & $\mathrm{R} \$$ & $\mathbf{9 7 3 . 1 8 7 , 8 3}$ & $\mathbf{8 , 6 3}$ \\
\hline
\end{tabular}

Fonte: Elaborado pelo autor, com informações do TCE/MT.

A única exceção nesse período foi o ano de 2012 em que, em termos percentuais, a arrecadação do IPTU representou apenas 6,64\% da Receita Tributária do município, mesmo que em valores nominais o montante arrecadado tenha sido maior que o ano anterior.

Em valores nominais o crescimento foi constante em todo o período analisado. $\mathrm{O}$ destaque, em valores nominais, fica para o ano de 2013 em que ocorreu o maior crescimento da receita do IPTU. Já o montante da Receita Tributária foi crescente em todo o período, mas teve um decréscimo no ano de 2013, quando comparamos com o ano de 2012.

Pela tabela 2 acima nota-se que a Receita Tributária Municipal de Mirassol D’Oeste, no período estudado, teve uma variação positiva de $65,12 \%$ enquanto no mesmo período a arrecadação do IPTU variou positivamente em 83,40\%. Fica evidenciado que nesse município a arrecadação por meio do IPTU superou a média de crescimento da arrecadação tributária.

Tabela 2 - Receita Tributária do Município de Mirassol D’Oeste de 2011 - 2014

\begin{tabular}{|c|c|c|c|}
\hline Mês & Receita tributária Municipal & $\begin{array}{c}\text { IPTU } \\
\text { Arrecadado em R\$ }\end{array}$ & $\begin{array}{c}\text { Representativida } \\
\text { de do IPTU \% }\end{array}$ \\
\hline
\end{tabular}




\begin{tabular}{c|c|c|c}
\cline { 3 - 4 } 2011 & $3.396 .848,29$ & $715.334,53$ & 21,06 \\
\hline 2012 & $3.697 .004,50$ & $772.798,27$ & 20,90 \\
\hline 2013 & $4.360 .828,54$ & $904.629,12$ & 20,74 \\
\hline 2014 & $5.608 .853,95$ & $1.311 .959,23$ & 23,39 \\
\hline Total & $\mathbf{1 7 . 0 6 3 . 5 3 5 , 2 8}$ & $\mathbf{3 . 7 0 4 . 7 2 1 , 1 5}$ & $\mathbf{2 1 , 7 1}$ \\
\hline
\end{tabular}

Fonte: Elaborado pelo autor, com informações do TCE/MT.

Já em termos de representatividade do IPTU em relação ao Receita Tributária Municipal do Município de Mirassol D’Oeste também houve crescimento, ou seja, a Receita Tributária do município cresceu, mas a arrecadação por meio do IPTU cresceu ainda mais. Os números demonstram que no ano de 2011 o IPTU representava 21,06 e no ano de 2014, último ano estudado, esse percentual era de $23,39 \%$.

Ocorre que dentro do período analisado os anos de 2012 e 2013 tiveram uma queda de representatividade do IPTU. Em 2012 o IPTU representou 20,90\% e em 2013 caiu ainda mais representando tão somente $20,74 \%$ de toda a receita tributária própria do município.

Em valores nominais o crescimento foi constante em todo o período analisado. $\mathrm{O}$ destaque, em valores nominais, fica para o ano de 2014 em que ocorreu o maior crescimento da receita do IPTU. Este crescimento foi acompanhado também de um crescimento relevante do total da Receita Tributária no mesmo ano.

No período estudado, conforme demonstrado na tabela 3, a receita tributária do município de São José dos Quatro Marcos sofreu uma variação positiva de apenas 17,74\% enquanto a arrecadação por meio do IPTU cresceu no mesmo período 80,84\%. Já em termos de representatividade do IPTU em relação ao Receita Tributária Municipal a mesma era de 7,39 e encerrou o período analisado em $11,35 \%$.

Tabela 3 - Receita Tributária do Município de São José dos Quatro Marcos 2011 - 2014

\begin{tabular}{c|cc|cc|c}
\hline Mês & \multicolumn{2}{|c|}{ Receita tributária Municipal } & \multicolumn{2}{c|}{ IPTU } & Representatividade do IPTU \\
\hline 2011 & $\mathrm{R} \$$ & $2.143 .188,73$ & $\mathrm{R} \$$ & $158.343,81$ & 7,39 \\
\hline 2012 & $\mathrm{R} \$$ & $2.043 .829,35$ & $\mathrm{R} \$$ & $188.913,49$ & 9,24 \\
\hline 2013 & $\mathrm{R} \$$ & $2.918 .713,32$ & $\mathrm{R} \$$ & $264.762,17$ & 9,07 \\
\hline 2014 & $\mathrm{R} \$$ & $2.523 .300,59$ & $\mathrm{R} \$$ & $286.342,44$ & 11,35 \\
\hline Total & $\mathbf{R} \$$ & $\mathbf{9 . 6 2 9 . 0 3 1 , 9 9}$ & $\mathbf{R} \$$ & $\mathbf{8 9 8 . 3 6 1 , 9 1}$ & $\mathbf{9 , 3 3}$ \\
\hline
\end{tabular}

Fonte: Elaborado pelo autor, com informações do TCE/MT.

A única exceção nesse período foi o ano de 2013 em que, em termos percentuais, a arrecadação do IPTU representou apenas 9,07\% da Receita Tributária do município, mesmo que em valores nominais o montante arrecadado tenha sido maior que o ano anterior. 
Em valores nominais o crescimento foi constante em todo o período analisado. $\mathrm{O}$ destaque, em valores nominais, fica para o ano de 2013 (comparado com o ano anterior) em que ocorreu o maior crescimento da receita do IPTU, mesmo tendo tido menor representatividade dentro da Receita Tributária. Este crescimento foi acompanhado também de um crescimento relevante do total da Receita Tributária no mesmo ano, razão pela qual em termos percentuais foi o ano em que o IPTU apresentou menor representatividade.

Em 2014, quando comparamos com o ano anterior, o município teve uma queda acentuada, da receita tributária. Já o IPTU em valores nominais continuou crescendo, tendo sido assim, ainda mais relevante para a composição do montante da Receita Tributária do município.

Percebe-se que a representatividade do IPTU diante das receitas tributárias municipais é crescente em todos os municípios analisados. No cenário de crise econômica a administração municipal buscou neste tributo uma maneira de arrecadar mais. Outro fator a ser destacado é que no ano de 2012, em dois municípios, houve queda na representatividade do IPTU, o que pode ter relação com o ano de eleições municipais.

\section{Gráfico 1 - Montante Arrecadado com IPTU - 2011 à 2014}

\section{Montante Arrecadado com IPTU 2011 à 2014}

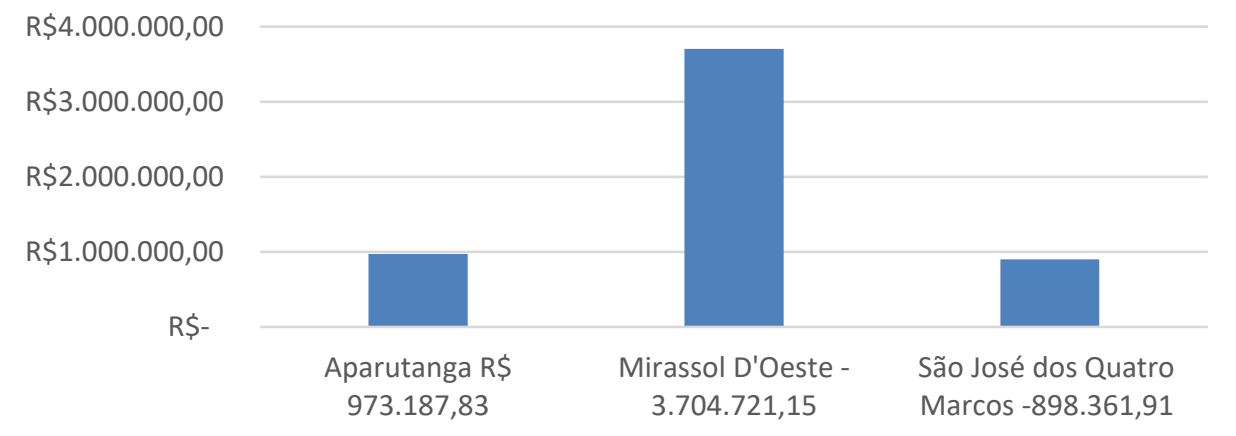

Fonte: Elaborado pelo autor, com informações do TCE/MT.

O estudo nos mostra que o montante arrecadado pela administração pública do município de Mirassol D’Oeste é bem superior aos outros municípios, mesmo com condições socioeconômicas semelhantes. Enquanto os municípios de Araputanga e São José dos Quatro Marcos arrecadaram menos que um milhão de reais no período o município de Mirassol D’Oeste arrecadou mais de três milhões e setecentos mil.

Esses dados demonstra que, apesar de um PIB semelhante, o contribuinte do município de Mirassol D’Oeste fica com um ônus bem superior aos outros municípios. No período 
mencionado em média o município de Mirassol D’Oeste arrecadou no período o valor de R\$ 139,30 por habitante enquanto os demais ficaram muito abaixo desse valor, não chegando a sequer 50\%. Em Araputanga esse valor foi de R\$ 60,41 e em São José dos Quatro Marcos apenas $\mathrm{R} \$ 48,47$. Apesar das particularidades com relação ao preço de mercado dos imóveis urbanos, é nítido que o contribuinte de Mirassol D’Oeste tem um dispêndio financeiro bem maior.

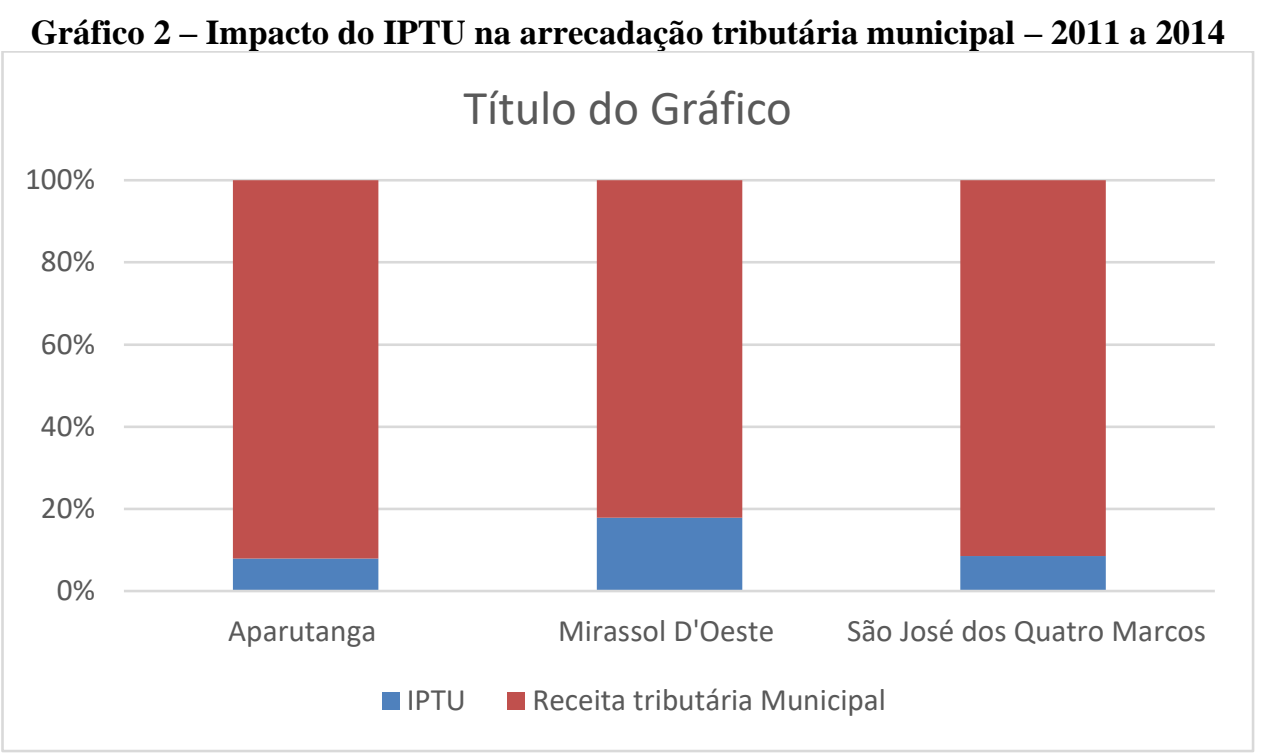

Fonte: Elaborado pelo autor, com informações do TCE/MT.

Ao analisar em conjunto os dados dos três municípios fica evidenciado que o impacto do IPTU para a arrecadação tributária municipal é relevante em todos eles. Sendo que no município de Mirassol D’Oeste esse impacto é bem maior, em média 21,71\% de toda a arrecadação tributária foi originada desse tributo. É necessário ressaltar que este tributo tem o fato gerador anual, sendo cobrado apenas uma única vez.

\section{CONSIDERAÇÕES FINAIS}

A mecânica da administração pública consiste em assegurar que todo o desembolso financeiro que os contribuintes fazem em proveito do Estado retornem por meio de prestação de serviços e bens que atinjam a coletividade de forma a garantir a supremacia do interesse público em detrimento do interesse particular. Nos últimos anos esses serviços tem se tornado mais eficientes em razão do crescimento do grau de instrução das pessoas e do acesso a informação facilitado pela tecnologia da informação. É o acompanhamento da gestão pública pelo cidadão que acaba por promover a transparência fiscal. Mesmo assim nem sempre o dinheiro público chega a sua destinação como deveria. 
Com uma inflação acumulada no período de $24.65 \%$, o crescimento da arrecadação do IPTU nesses municípios cresceu em média 44,29\% (São José dos Quatro Marcos 44,70\%; Mirassol D'Oeste 45,48\%; Araputanga 42,69\%).

O resultado da pesquisa demonstra que os recursos arrecadados com o IPTU são essenciais para os três municípios e que representam quase $10 \%$ de recursos da arrecadação tributária dos municípios de São José dos Quatro Marcos e de Araputanga. No caso do município de Mirassol D’Oeste essa fonte de recurso é ainda mais relevante e representativa, pois em média mais de $21 \%$ da arrecadação tributária do município é originada do IPTU.

Os dados nos mostram que no período analisado (2011 - 2014) o município de Araputanga sofreu uma pequena variação nos índices de crescimento da arrecadação por meio do IPTU, quando comparado com a Receita Tributária própria. Podemos assim perceber que não houve uma política de melhoria no sistema de arrecadação permanecendo praticamente estável no decorrer dos cinco anos.

Em contrapartida o município de Mirassol D’Oeste apresentou um grande crescimento na arrecadação do IPTU. O crescimento na arrecadação do IPTU acompanhou o aumento na Receita Tributária própria do município o que demonstra a implantação de uma política voltada para valorização da Receita Própria como maneira de obter recursos para saldar as demandas da administração pública municipal.

Como sugestão de pesquisa fica uma análise qualitativa dessa informação gerada para entender esses valores tão díspares em municípios com um perfil sócio econômico bem semelhante.

\begin{abstract}
The Municipal Tax Revenue and the collection of the Urban Territorial Property Tax (IPTU) from the municipalities of Araputanga, Mirassol D'Oeste and São José dos Quatro Marcos, in the period from 2011 to 2014, were the object of study of this academic work. The selected municipalities are part of the micro-region designated Vale do Jauru, west of the State of Mato Grosso, and have similar geographic and social characteristics. The objective was to analyze the representativeness of this tax for the amount of the own tax collection. In the data collection phase, a quantitative survey was carried out on the websites of municipalities; municipalities and the Court of Accounts of the State of Mato Grosso, where the amount collected in Tax Revenue and the specific value of the IPTU were investigated. As for the method of analysis, the quantitative method was used, and a descriptive analysis of the data was performed. It was observed that this source of appeal is relevant to the Tax Revenue of the municipalities under analysis
\end{abstract}

Keywords: IPTU, Public Management, Municipal Tax Revenue. 


\section{REFERÊNCIAS}

AFONSO, José Roberto Rodrigues; ARAÚJO, Érika Amorim. A capacidade de gasto dos municípios brasileiros: arrecadação própria e receita disponível. 2001.

BEUREN, Ilse Maria. et al. Como elaborar trabalhos monográficos em Contabilidade: Teoria e Prática. 3.ed. São Paulo: Atlas, 2006.

BRASIL. Lei 5.172, de 25 de outubro de 1966. Dispõe sobre o Sistema Tributário Nacional e institui normas gerais de direito tributário aplicáveis à União, Estados e Municípios. Código Tributário. Diário Oficial da União, Brasília, 27 out. 1966. 1988.

. Constituição (1988). Constituição da República Federativa do Brasil. Brasília, DF.

Ministério do Planejamento e de Desenvolvimento. Manual de Orientação para Crescimento da Receita Própria Municipal. Brasília (DF), 2001.

CARVALHO JR, Pedro Humberto Bruno de. IPTU no Brasil: progressividade, arrecadação e aspectos extra-fiscais. 2006.

CORRÊA, Alexandre Augusto de Castro. Notas sobre a história dos impostos em direito romano. Revista da Faculdade de Direito, Universidade de São Paulo, v. 66, p. 97-104, 1971.

DALFOVO, Michael Samir; LANA, Rogério Adilson; SILVEIRA, Amélia. "Métodos quantitativos e qualitativos: um resgate teórico." Revista Interdisciplinar Científica Aplicada 2.3 (2008): 1-13.

DUARTE, Evaldo Rezende. GESTÃO TRIBUTÁRIA: A importância da Receita Tributária Própria no Orçamento dos Municípios do Vale do São Lourenço, no período de 2010 a 2012. 2014.

GIL, Antonio Carlos. Metodologia do ensino superior. 3. ed. São Paulo: Atlas, 1997.

Como elaborar projetos de pesquisa. 4.ed. São Paulo: Atlas, 2002.

GODOY. Arilda Schmidt. Pesquisa Qualitativa: tipos fundamentais. Revista de Administração de Empresas. p. 20-29, 1995.

JUNQUEIRA L.A.; INOJOSA, R. M.; KOMATSU, S. Descentralização e intersetorialidade: na gestão pública municipal no Brasil: a experiência de Fortaleza. Caracas: UNESCO/CLAD, 1998. Série Concurso de Ensayos CLAD.

MAZOYER, Marcel; ROUDART, Laurence. História das Agriculturas do Mundo: do Neolítico à Crise Contemporânea. Trad. Cláudia F. Falluh Balduino Ferreira. São Paulo/Brasília: Edunesp/NEAD/MDA, 2010. 
NAZARETH, P.A. e Porto, L.F.L., "As Finanças dos Municípios Brasileiros: o caso do Rio de Janeiro", artigo publicado no "XIV Seminário Regional de Política Fiscal - Compendio de Documentos - 2002”, CEPAL, Chile, janeiro/2002.

OLIVEIRA, Robson Eneas de. Avaliação de impacto do Programa de Modernização Tributária e da Gestão dos Setores Sociais Básicos (PMAT) na arrecadação de ISSQN e IPTU dos municípios, no período de 1999 a 2011. Biblioteca Digital, FGV. 2015.

SIQUEIRA, Rozane Bezerra de; NOGUEIRA, José Ricardo; SOUZA, Evaldo Santana de. A incidência final dos impostos indiretos no Brasil: efeitos da tributação de insumos. Revista brasileira de economia, v. 55, n. 4, p. 513-544, 2001. 